Cad.Est.Ling., Campinas, (41):75-89, Jul./Dez. 2001

\title{
A REFERENCIAÇÃO COMO ATIVIDADE COGNITIVO-DISCURSIVA E INTERACIONAL
}

\author{
INGEDORE G. VILLAÇA KOCH \\ UNICAMP/CNPQ
}

\begin{abstract}
This paper aims to discuss the cognitive, resumptive, cohesive, organizational and avaliative functions performed by nominal expressions occurring in referential chains, in order to highlight their contribution to the argumentative orientation of texts, and, by consequence, to the construction of meaning.
\end{abstract}

\section{INTRODUÇÃO}

Este artigo tem por objetivo levantar algumas questões relacionadas à referenciação quando efetuada por meio de formas ou expressões nominais. Partirei, para tanto, dos seguintes pressupostos:

1. a referenciação é uma atividade cognitivo-discursiva e interacional, realizada por sujeitos sociais;

2. os "referentes" não são "coisas" do mundo real, mas objetos de discurso, construídos no decorrer dessa atividade;

3. o processamento do discurso, por ser realizado por sujeitos ativos, é estratégico, isto é, implica, da parte dos interlocutores, a realização de escolhas significativas entre as múltiplas possibilidades que a língua oferece.

\section{CONCEITUAÇÃO}

Como se sabe, denominam-se formas nominais as formas lingüísticas constituídas, minimamente, de um determinante (que pode ser um $\phi$ ) seguido de um nome (substantivo). A estrutura e função desses grupos nominais com função referencial, sobretudo a questão da seleção do determinante - artigo ou demonstrativo - e do seu comportamento textual-discursivo em cada caso, vem merecendo, na minha pesquisa atenção especial. As estratégias que vou enfocar aqui são as do uso de descrições definidas, de formas resultantes de nominalização - incluindo as que constituem algum tipo de rotulação metalingüística ou metadiscursiva (cf. Francis, 1994; Conte, 1991, 
1993; Koch, 1998, 1999) -, bem como daquelas expressões que funcionam no texto como anáforas indiretas.

Ao colocar em ação a estratégia da descrição definida, opera-se uma seleção, dentre as propriedades passíveis de serem atribuídas a um referente, daquela(s) que, em dada situação discursiva, é (são) relevante(s) para o locutor, tendo em vista a viabilização do seu projeto de dizer . Por meio da estratégia da nominalização erigemse em objetos de discurso conjuntos de informações presentes no texto precedente. As anáforas indiretas, por seu turno, caracterizam-se pelo fato de não existir no co-texto um antecedente explícito, mas sim um elemento de relação (por vezes uma estrutura complexa), que se pode denominar âncora (cf. Schwarz 2000) e que é decisivo para a interpretação; ou seja, trata-se de formas nominais que se encontram em dependência interpretativa de determinadas expressões da estrutura textual em desenvolvimento, o que permite que seus referentes sejam ativados por meio de processos cognitivos inferenciais que mobilizam conhecimentos dos mais diversos tipos armazenados na memória dos interlocutores. As anáforas indiretas, como veremos, são responsáveis pelos dois fatores básicos de progressão textual: a introdução de novos referentes, isto é, a inserção de referentes na estrutura de referencialização mental, o que vai acarretar uma ampliação do modelo textual, pela criação de um novo nódulo informacional; e a retomada ou reativação, responsável pela continuidade referencial, ou seja, a remissão constante aos mesmos domínios de referência, garantindo a prosseqüência do quadro referencial global. É o que acontece, por exemplo, com a expressão o magistrado, em (1):

(1) "A Justiça dos EUA decidiu ontem, em caráter liminar, suspender a efetividade de uma lei que previa retirar da Internet sites que oferecessem material pornográfico gratuitamente (...).

"O magistrado, de uma corte de Filadélfia, aceitou os argumentos de críticos da Lei de Proteção On Line à Criança, que dizem que ela poderia cercear a liberdade de expressão na Internet”. (Folha de São Paulo, 3/2/1999).

As anáforas indiretas desempenham um papel extremamente importante na construção da coerência. Muitas vezes, por ocasião do processamento textual, existem diversas representações tópicas potenciais e, somente no co-texto subseqüente, fica claro, por meio do encadeamento referencial efetuado, qual delas deve ser selecionada na interpretação.

Um ponto pouco discutido na literatura sobre referenciação e que eu gostaria de ressaltar aqui é que a progressão referencial pode realizar-se, também, pelo uso de expressões nominais indefinidas com função anafórica (e não, como é mais característico, de introdução de novos referentes textuais). Vejam-se, no exemplo (2), as expressões que referenciam o protagonista e como esse referente vai sendo polifonicamente! - construído textualmente, nessa operação dupla de referenciação e progressão temática:

"Leio no jornal a notícia que um homem morreu de fome(...) 
"Um homem morre em plena rua, entre centenas de passantes. Um homem caído na rua. Um bêbado. Um vagabundo. Um mendigo, um anormal, um tarado, um pária, um marginal, um proscrito, um bicho, uma coisa - não é um homem. E outros homens cumprem o seu destino de passantes, que é o de passar. (...)"(Sabino, F., A mulher do vizinho, $8^{\mathrm{a}}$ ed., Rio de Janeiro: Record, 1962).

Observem-se, também, os exemplos (3) e (4). Mais adiante, voltarei a essa questão.

(3) “(...) Se há fuga de divisas para o exterior e as ações despencam, os reflexos na sociedade são imediatos.

"Um exemplo clássico foi a quebra da Bolsa de Valores de Nova Iorque em 1929, quando todo o mercado internacional se ressentiu (...) ("Crise na Bolsa não ensinou brasileiro", A Tribuna de Campinas, 17/5/1998).

(4) O assassino havia encontrado sua próxima vítima. No dia seguinte, a polícia encontrou uma mulher estrangulada no parque central da cidade...

\section{PRINCIPAIS FUNÇÕES DAS FORMAS NOMINAIS REFERENCIAIS NA PROGRESSÃO TEXTUAL}

Venho postulando para as formas referenciais nominais funções de diversas ordens no texto, cujo estudo merecerá ainda um aprofundamento maior. Entre elas, podem-se destacar as seguintes:

\section{- $\quad \underline{\text { Cognitivas }}$}

As formas referenciais definidas desempenham funções cognitivas de extrema relevância para o processamento textual:

1. como formas de remissão a elementos anteriormente apresentados no texto ou sugeridos pelo co-texto precedente, elas possibilitam a sua (re)ativação na memória do interlocutor, ou seja, a alocação ou focalização na memória ativa (ou operacional) deste;

2. por outro lado, ao operarem uma recategorização ou refocalização do referente ou, em se tratando de nominalizações, das informações-suporte, elas têm, ao mesmo tempo, função predicativa. Trata-se, pois, de formas híbridas, referenciadoras e predicativas, isto é, veiculadoras tanto de informação dada, como de informação nova. Schwarz (2000) denomina essa operação de tematização remática.

- Encapsulamento ou sumarização 
Esta é uma função própria particularmente das nominalizações que, conforme foi mencionado, sumarizam as informações-suporte contidas em segmentos precedentes do texto, encapsulando-as sob a forma de um substantivo-predicativo e transformando-as em objetos-de-discurso.

Trata-se nesses casos, segundo Schwarz (2000), de anáforas “complexas”, que não nomeiam um referente específico, mas referentes textuais abstratos, como ESTADO, FATO, EVENTO, ATIVIDADE etc. Trata-se, como se pode ver, de nomes-núcleo inespecíficos, que exigem realização lexical no co-texto. Essa especificação vai constituir uma seleção particular e única dentre uma infinidade de lexicalizações possíveis, efetuada a partir das proposições veiculadoras das informações-suporte. A interpretação dessas anáforas obriga o receptor não só a pôr em ação a estratégia cognitiva de formação de complexos, como ainda lhe exige a capacidade de interpretação de informação adicional. Tais expressões nominais, que são, em sua maior parte, introduzidas pelo demonstrativo, desempenham duas funções: rotulam uma parte do co-texto que as precede e estabelecem um novo referente que, por sua vez, poderá constituir um tema específico para os enunciados subseqüentes. É esta a razão por que, freqüentemente, aparecem em início de parágrafos.

- De organização textual

a. no nível microestrutural

As formas nominais referenciais constituem recursos coesivos dos mais produtivos na construção da textualidade, podendo funcionar quer anafórica, quer cataforicamente. Há, mesmo, casos em que são simultaneamente anafóricos e catafóricos. (cf. o exemplo (3)).

b. no nível macroestrutural

Como bem mostra Francis (1994:87), as formas remissivas nominais têm uma função organizacional importante: elas sinalizam que o autor do texto está passando a um estágio seguinte de sua argumentação, fechando o anterior por meio de seu encapsulamento em uma forma nominal. Possuem, portanto, uma importante função na introdução, mudança ou desvio de tópico, bem como de ligação entre tópicos e subtópicos. Ou seja, elas introduzem mudanças ou desvios do tópico, preservando, contudo, a continuidade tópica, ao alocarem a informação nova dentro do quadro da informação dada. Desta forma, são responsáveis simultaneamente pelos dois grandes movimentos de construção textual: retroação e progressão.

Assim sendo, como também apontam Apothéloz \& Chanet (1997:170), as expressões referenciais efetuam a marcação de parágrafos, incrementando, desta forma, a estruturação do produto textual. Ressaltam que não se trata aqui de parágrafo no sentido tipográfico, mas no sentido cognitivo do termo, embora, evidentemente, as duas coisas possam coincidir. Observe-se o exemplo (5): 
(5) “(...) A gravidade na superfície do astro em contração vai mais e mais aumentando e, a partir de um certo ponto, até mesmo a luz não consegue mais escapar-lhe. Formase, então, um buraco negro.

"Esse nome tem sua origem na interpretação oriunda da Teoria da Relatividade sobre a interação gravitacional. Dentro dessa teoria, a gravidade nada mais é que o resultado da curvatura do espaço ao redor de um corpo com massa.

"Num buraco negro, o espaço curvou-se tanto que acabou fechando-se sobre si mesmo. (...) (Romildo Póvoa Faria, "Buracos Negros", A Tribuna de Campinas, $17 / 5 / 1998)$

\section{OS DETERMINANTES NAS EXPRESSÕES REFERENCIAIS}

$\mathrm{Na}$ reativação de referentes textuais, a seleção do determinante desempenha papel de destaque, dado que o tipo de determinação das expressões nominais estabelece relações referenciais específicas (Schwarz, 2000). Existe uma literatura bastante alentada sobre a semântica e a pragmática dos determinantes, especialmente do artigo definido (Vater, 1979, 1984, 1996; Hawkins, 1978; Kleiber, 1983 a, b; 1984; Cornish, 1987; entre vários outros), mas os critérios aí apresentados, tais como unicidade, identificabilidade, localizabilidade etc. - com algumas exceções, é claro - abarcam apenas um pequeno espectro do fenômeno.

Quanto aos três usos mais freqüentemente apontados para o demonstrativo dêitico, anafórico e dêitico memorial -, Béguelin (1998) distingue as posições do locutor e do alocutário. Na perspectiva do alocutário, os empregos situacionais e anafóricos são os mais fáceis de processar, na medida em que o referente já se encontra validado em sua memória discursiva, devido aos conhecimentos que ele tem do contexto em sentido amplo. No momento da ocorrência da forma nominal demonstrativa, a memória discursiva encerra tanto a informação de origem perceptual associada ao denotatum, quanto a informação construída por via verbal. Os pressupostos associados à forma lingüística esse $N$ são assim verificados pelo estado da memória discursiva, de modo que a competência inferencial do alocutário é apenas modestamente solicitada.

Ao contrário, no caso da dêixis memorial, o locutor, egocentricamente, se exime de adaptar a forma de seu discurso ao estado presumido de conhecimentos partilhados, utilizando a expressão demonstrativa "unilateralmente", de forma que cabe ao alocutário acomodar a posteriori a memória discursiva. Entra aqui em jogo um contrato de comunicação fundamentado não sobre a antecipação de dificuldades interpretativas, mas sim sobre o apelo à cooperação do alocutário, que deverá "verificar" por si mesmo os pressupostos inerentes à forma demonstrativa (cf. Zamponi, neste mesmo volume).

Apothéloz \& Chanet (1997: 167 ss.), bem como Apothéloz \& Reichler-Béguelin (1999) sugerem alguns fatores que favorecem o aparecimento de um artigo definido ou de um pronome demonstrativo como determinantes das formas nominais referenciais, embora reconheçam que, em um número considerável de contextos, as duas formas se encontram praticamente em variação livre. Contudo, o que determina o caráter 
complementar ou não de ambas, especialmente no que diz respeito ao português - que parece apresentar características diferentes de algumas outras línguas quanto ao uso do definido ou do demonstrativo - constitui objeto central de pesquisa não só de minha parte, como de outros pesquisadores como Cavalcante (2000) e Zamponi (2001).

\subsection{Uso do demonstrativo}

De acordo com Apothéloz \& Chanet, os casos em que se privilegiaria o emprego do pronome demonstrativo seriam, entre outros:

- casos em que a expressão referencial opera uma recategorização mais ou menos metafórica do processo, isto é, sempre que o substantivo escolhido requalifica o referente de forma pouco predizível:

(6) "Nestes tempos de crise e de cortes de gastos públicos, o presidente planeja dar uma cara mais moderna a seu governo (...).

"Mais do que essa operação plástica no governo, o que motiva uma queda-debraço entre os aliados é a criação de um superministério para cuidar da produção e comércio exterior (...)"(Isto é, 1518, 4/11/1998, p.33)

- casos de polifonia (Ducrot, 1980) ou heterogeneidade discursiva (Authier-Révuz, 1982), como, por exemplo, o discurso indireto livre e a denominação reportada, ou seja, sempre que o substantivo-núcleo da expressão referencial não é - ou não parece ser totalmente assumido pelo locutor, ou é empregado ironicamente, isto é, quando colocado entre "aspas de conotação autonímica" (Authier, 1981:136), como se pode ver em (7):

(7) Ao analisar os resultados do Sistema Nacional de Avaliação Básica do MEC, o ministro Paulo Renato Souza (Educação) afirmou que "a escola está cada vez mais chata, e o aluno cada vez mais dispersivo e indisciplinado". (...).

Para Paulo Renato, esse "efeito chatice" é provocado por duas razões centrais: a falta de reciclagem das escolas e a grande oferta de conhecimento fora da sala de aula, principalmente na Internet. (Folha de São Paulo, 29/11/2000).

- casos em que o nome-núcleo do SN vem modificado por um adjetivo na função de adjunto adnominal - não pertinente para a identificação do referente, mas importante do ponto de vista da argumentação (exemplo 8). Caso se queira de qualquer forma usar o definido, será necessário, modificar o seu estatuto sintático, transformando-o em aposto, como em (9):

(8) A Polícia Militar, durante uma blitz, prendeu hoje vários moradores da favela da Rocinha. Essa detenção brutal e sem motivo declarado revoltou os moradores do lugar. 
(9) A Polícia Militar, durante uma blitz, prendeu hoje vários moradores da favela da Rocinha. A detenção - brutal e sem motivo declarado - revoltou os moradores do lugar.

- casos de SNs associativos em que o demonstrativo não seria passível de substituição por um definido, visto que, se isto acontecesse, teriam alterado seu valor referencial ou se criariam dificuldades relativamente sérias para se chegar a uma interpretação adequada. Observe-se o exemplo (10):

(10) Os caminhoneiros fizeram uma paralisação, bloqueando totalmente as principais rodovias do território nacional. Considere-se que esse meio de transporte é vital para a economia do país.

- Nos casos de uso de hiperônimos, quando se pretende evitar uma referência genérica:

(11) A antiga Estação Sorocabana, em São Paulo, foi transformada em uma das mais modernas salas de concerto do mundo. Essa arte vinha exigindo maior incentivo de parte das autoridades públicas.

- casos de marcação de parágrafo: o fato de ser comum encontrar expressões referenciais nominais em fronteira de parágrafos decorre de uma estratégia que consiste em balizar as fases mais importantes do discurso, para facilitar não apenas a sua recepção, mas também a sua produção. Nesse caso, a visibilidade das expressões referenciais é utilizada como recurso para incrementar a estruturação textual. A referência demonstrativa é justamente um meio de tornar perceptivelmente saliente uma expressão. Por esta razão, as nominalizações demonstrativas são comuns nos momentos em que se produz uma mudança de ponto de vista e contribuem para marcar essa transição. (cf. o exemplo (5)).

- casos de referência problemática: o referente da expressão anafórica possui, em geral, um alto grau de predizibilidade e, portanto, de acessibilidade, Isto é, o referente pode ser facilmente inferido com base no co-texto prévio e/ou no contexto de uso, de forma que sua presença na memória discursiva pode ser considerada latente no momento em que a anáfora aponta para ele. Contudo, os referentes são, por vezes, menos predizíveis e até mesmo impredizíveis, obrigando o receptor a introduzir um novo objeto em sua memória discursiva e construir a informação contextual de modo a permitir que esta introduçào seja consistente e compatível com o estado atual daquela. Neste caso, o uso do demonstrativo seria praticamente obrigatório, como em (12):

(12) "As lideranças sindicais estão promovendo, em todo o território nacional, mutirões de esclarecimento da população sobre a aflitiva situação do país e as alternativas possíveis para enfrentá-la. Só esta tomada de consciência, que se vem fazendo necessária há tanto tempo, poderá levar a mudanças significativas”. 
Em suma: um dos efeitos produzidos pelo demonstrativo é o de recuperar a informação do co-texto à esquerda. É por isso que os SNs demonstrativos podem ser facilmente parafraseados por um SN seguido de um adjunto adnominal ou de uma oração relativa que venham a atualizar tal informação. Este fenômeno é claramente verificável quando o núcleo nominal do SN anafórico é um nome de processo, por terem estes valor semântico incompleto, sendo, pois, intrinsecamente anafóricos. Quando introduzidos por um determinante demonstrativo, este acarreta a captação dos argumentos do processo por meio da referência.

\subsection{Uso do artigo definido}

Favoreceriam, entre outros casos, o aparecimento do artigo definido:

- $\quad$ presença no interior do SN anafórico de um adjunto adnominal ou complemento nominal que designa um dos actantes do processo (mais freqüentemente o Objeto):

(13) "O cronômetro começou a correr. Quando o ministro da Fazenda, Pedro Malan, anunciou na quarta-feira 28 o tão adiado pacote fiscal para desarmar a bomba que pode detonar o Real, o governo iniciou, mais uma vez, uma corrida contra o relógio. Em menos de um ano, foi o segundo pacotão em seguida a uma alta estratosférica de juros.

"O palco do anúncio, o auditório do Ministério da Fazenda em Brasília, foi o mesmo.”(Isto é, 1518, 4/11/1998, p. 27).

- $\quad$ substantivos predicativos morfologicamente derivados de verbo que figuram na proposição nominalizada:

(14) "O Ministério da Saúde adverte: o cigarro causa impotência". A advertência vem acrescentar mais um dano aos que vinham sendo anteriormente anunciados.

- nomes predicativos que designam um atributo da enunciação, isto é, nominalizam um processo, mas não aquele denotado pelo conteúdo proposicional e sim o tipo de ato de comunicação realizado por sua enunciação, categorizando-o de determinada forma:

(15) O presidente afirmou em recente entrevista que não é um neoliberal, mas que defende um Estado Moderno (...). A explicação não convenceu os presentes.

- Casos em que o substantivo predicativo é um nome genérico, como coisa, fato, evento etc., especialmente quando não seguido de uma expansão determinativa e se encontra em posição temática:

(16) Mais um condenado é levado à cadeira elétrica nos EUA. A cena foi filmada pela TV americana e chocou os telespectadores. 
Com base em análise prévia, parece ser possível afirmar que o português tem, em diversos desses casos, um comportamento diferente, pelo menos relativamente ao francês e ao alemão: poder-se-ia dizer, à primeira vista, que nossa língua é mais "tolerante" quanto à intercambialidade do demonstrativo e do definido. Basta, por exemplo, retomar os exemplos aqui apresentados, que permitirão verificar que, a par de casos categóricos de emprego de uma e outra dessas formas, parece haver uma extensa faixa intermediária em que eles se encontram em variação livre.

\subsection{Uso do artigo indefinido}

As expressões nominais introduzidas por artigo indefinido não são normalmente adequadas para a retomada de referentes já apresentadas no texto. Contudo, como foi destacado anteriormente, elas podem, em certas circunstâncias, desempenhar tal função. São três os principais desses casos (cf. Schwarz, 2000:59-60):

- quando se seleciona um referente no interior de um conjunto já mencionado:

(17) Um grupo de colegiais entrou na sala. Um estudante loiro acenou para mim.

- quando se nomeiam partes de um referente previamente mencionado (exemplo 18) ou, então, conscientemente, não se especifica melhor o referente, para criar um efeito de suspense (exemplo 19):

(18) Preciso consertar o telhado. Uma telha está quebrada.

(19) Assalto a Banco: os meliantes atiram no motorista de um carro forte. O caixa age com a rapidez de um raio: fazendo o dinheiro desaparecer não se sabe como, apresenta aos assaltantes duas caixas vazias. À noite, ele recebe uma visita inesperada. No dia seguinte, um cadáver é retirado de um riacho próximo.(exemplo adaptado de Schwarz, 2000:59).

- quando a expressão anafórica focaliza mais fortemente a informação por ela veiculada do que o prosseguimento da cadeia coesiva:

(20) A velha senhora desaba sobre a cadeira da cozinha. E quando sua amiga chega, não encontra a avozinha, mas um montinho de infelicidade, uma coisinha danificada e confusa. (adaptado de Schwarz, 2000:59)

\section{IMPORTÂNCIA DAS ESCOLHAS LEXICAIS NA CONSTRUÇÃO DAS EXPRESSÕES REFERENCIAIS}

A escolha do nome-núcleo e/ou de seus modificadores vai ser o responsável pela orientação argumentativa do texto. 
Nome-núcleo:

1. Genérico, conforme foi dito, nas nominalizações e também, muitas vezes, nas rotulações de seqüências textuais anteriores, mas assim mesmo dotado de carga avaliativa:

(21) (...) "O problema reside no ponto de vista em que da virtude se passa ao vício. Procuradores ou promotores por vezes não têm feito o melhor uso de sua função. Alguns utilizam-se do cargo apenas para ganhar visibilidade na mídia quando, mesmo desprovidos de indícios consistentes, lançam acusações que prejudicam terceiros, não raro de maneira irreversível. Há basicamente dois tipos de remédios para esses abusos". (Folha de São Paulo, 27/07/2000).

(22) "Na conversa que teria sido gravada em 19 de agosto, Miranda diz que o chefe ironizou a proposta, dizendo que não aceitaria como suborno "a metade de um terço do que fora anteriormente acordado, que os empresários caça-níqueis de Minas calculam em R\$ 6 milhões.

"O escândalo ocorreu uma semana depois da mais recente ação ostensiva de apreensão de máquinas em Belo Horizonte (...)” (Isto é, 06/09/2000).

2. metafórico, em muitos casos - a escolha da metáfora adequada é importante para realizar a avaliação e, em decorrência, estabelecer a orientação argumentativa do texto:

(23) "Hoje falaremos de dois brasileiros típicos da era do real. Zé das Couves, o primeiro, é pobre. (...). Walter Moreira Salles, o segundo, é milionário (...).

"O real do professor Cardoso foi concebido para facilitar a vida da tribo de Zé das Couves e para infernizar o cotidiano da trupe de Moreira Salles" (Josias de Souza, "De bancos e geladeiras", FSP, 22/11/95).

(24) "Em artigo recentemente publicado pelo professor Marcos Cintra no 'Jornal da Tarde' (1 /11/2000), verifica-se que os brasileiros são forçados a pagar cerca de 35\% de impostos nos alimentos que consomem - enquanto a média internacional é de apenas $7 \%$.

Isso é um verdadeiro absurdo! Um país que tem tantos recursos naturais e tanta capacidade de produzir safras agrícolas (...).

A gula tributária parece que não tem fim. Já ultrapassou a casa dos $30 \%$ do PIB quando em países de renda mínima como o Brasil ela não passa de $24 \%$. (...).

O mais escandaloso nisso tudo é saber que, nos últimos três anos, a receita do Imposto de Renda - sozinha - saltou de R 18 bilhões para mais de 34 bilhões (...)."

(25) "De lá para cá o PT passou a ser atacado por suas brigas internas, mal que o acomete até hoje. 
Outra pedra lançada na vidraça petista é a de que o partido só sabe criticar, sem propor nada." (Isto é, 11/10/2000).

3. metonímico ou meronímico, no caso da anáforas associativas. Em muitos casos, inclusive, um novo referente textual é construído metonimicamente, como em (26):

(26) "Estávamos todos, aqui da vizinhança, acostumados a vê-lo, parado em frente à casa dos gatos.

Eu o conhecia havia quatro anos.

Quieto, acabrunhado, um farol arrebentado, a pintura que foi gelo adquirindo cor macilenta. Estilhaços de ferrugem. Os pneus duraram algum tempo, murcharam carecas. Os cromados cheios de pontos negros.

Mas os vidros, misteriosamente intactos.

O Fusquinha acabou uma espécie de mascote.(...) Ignacio de Loyola Brandão, Agora há um vazio na rua).

4. introdutor "clandestino" de referentes:

(27) “(...) no gramado daquele luxuoso hotel estava montada uma gigantesca tenda verde, cercada por guarda-costas armados até os dentes. Nela estava alojado ninguém menos que o todo-poderoso homem forte da Líbia, o coronel Muammar Gadafi, que se recusara a ficar hospedado no Sheraton alegando que este representava um símbolo do imperialismo americano". " $O$ gesto circense do ditador líbio não chegou a surpreender..." (Isto é, 06/09/2000).

\section{1. metadiscursivo}

A recategorização de referentes pode ser realizada, ainda, por meio de formas metalingüísticas ou metadiscursivas (cf. Francis, 1994). Entre tais formas podem-se mencionar:

- nomes "ilocucionários", como: ordem, promessa, conselho, advertência, afirmação, asserção, crítica, proposta, alegação, cumprimento, etc.:

- nomes de atividades "linguageiras": descrição, explicação, relato, esclarecimento, resumo, história, debate, exemplo, ilustração, definição, denominação, etc.:

- nomes de processos mentais: análise, suposição, atitude, opinião, conceito, convicção, avaliação, constatação, etc. :

- nomes metalingüísticos em sentido próprio: frase, pergunta, questão, sentença, palavra, termo, parágrafo etc.

- denominação reportada: por meio da denominação reportada (citação de de termos ou expressões), introduz-se no texto a fala do Outro, mantendo, com relação a ela, um distanciamento crítico, assinalado pelas aspas de conotação autonímica (Authier, 1981). 
Observem-se os exemplos:

(28) (...) "O programa mata a fome, mas não ajuda a diminuir a pobreza nem estimula a economia das regiões mais carentes, diz Terra, a propósito do corte das cesta básicas para as famílias mais pobres.

"Tem-se, nessa única sentença, os dois lados essenciais do governo FHC. Primeiro, o academicismo. Segundo, o economicismo." (Clóvis Rossi, O retrato de um governo, FSP, 28/11/00)

(29) L1: ...anos atrás eu bolei um livro que nunca escrevi... compreendeu? tá todo pronto e jamais foi escrito em que: se discutia o desequilíbrio ecológico não se falava nem nisso há quinze vinte anos atrás... ninguém usava $a$ expressão desequilíbrio ecológico... o livro todo tava bolado...(D2 REC 05: 821-826).

\section{Seleção dos qualificadores: modificadores axiológicos positivos/negativos}

(30) (...) De que adianta reclamar da má distribuição de renda se os brasileiros não têm educação e saúde de qualidade, trabalho condigno e renda suficiente para fazer crescer suas famílias? Não é possível continuar com essa retórica falsa e maldosa. Isso afronta a razão humana e submete o povo e seus produtores ao sofrimento e à indignação." (Folha, 19/11/2000)

(31) Vários artistas populares expuseram seus trabalhos na galeria recém-inaugurada. $A$ excelente seleção feita pelos organizadores da exposição garantiu o sucesso total do evento.

\section{REFERENCIAÇÃO E ARGUMENTAÇÃO}

Pelo que foi exposto no item anterior, fica patente que a função de recategorização argumentativa pode ser realizada apenas por meio do nome-núcleo ou pelo acréscimo de modificadores avaliativos (positivos ou negativos), conforme pode ser observado, ainda, nos exemplos abaixo, que evidenciam a relação íntima entre referenciação por formas nominais e argumentação:

(32) "No Brasil, ao longo dos anos 80, várias vezes a proposta de 'pacto social' foi cogitada e até negociada, mas prevaleceram os acordos entre oligarquias, enquanto se agudizavam as resistências corporativistas.

“Ainda que esses 'pactos' sejam muitas vezes retóricos, os espanhóis têm a seu favor a capacidade de colocar também as questões sociais no âmbito da modernização política e econômica.”(Folha de São Paulo, 26/11/2000).

(33) "Hoje, Laerte desperta ódio e perplexidade. Friamente, confessou 11 assassinatos de crianças, entre quatro e dez anos. Duas outras mortes foram confessadas 
informalmente à polícia, até quinta-feira, 27. $\underline{O}$ "Monstro de Rio Claro", como passou a ser conhecido, gostava de registrar num caderno o dia e a cidade onde passava. (...) $\underline{O}$ andarilho da morte faz questão de dizer que tem profissão: é engraxador, de portas de estabelecimentos(...)" ( Istoé, 02/02/2000)

(34) "Fernando Henrique Cardoso não gosta de ser chamado de neo liberal. Quando alcançado por essa 'ofensa', responde, sempre irritado, que defende um Estado forte, dotado de poder de regulamentação, que não se confunde com o Estado desenvolvimentista, sempre inclinado a se meter onde não deveria.

Não seria justo chamar esse bate-boca de controvérsia de "nefelibatas". Descendo das nuvens, o panorama fica mais claro: nos quase seis anos de "política modernizadora", o governo FHC executou diligentemente as reformas que estão no cardápio do Consenso de Washington."

O consenso - ou, como prefere o economista inglês Peter Growan, o regime Dólar Wall Street - vem patrocinando na periferia do capitalismo (perdão pelo mau gosto) a abertura financeira e comercial, a desregulamentação, as privatizações, as tentativas de flexibilização dos mercados de trabalho.

Dessa gororoba reformista, nasce uma economia sem instrumentos de governança, não só manietada em sua liberdade de utilizar instrumentos fiscais e monetários para sustentar o crescimento a curto prazo, mas estruturalmente incapaz de engendrar estratégias virtuosas de longo prazo. (Folha de São Paulo, 19/11/2000)

\section{PARA CONCLUIR...}

Grande parte dos estudos sobre a referência textual têm-se ocupado excessivamente com a questão das restrições sobre a anáfora, sem levar em conta as funções semânticas, pragmáticas e interativas das diversas formas de expressões referenciais, que precisam ser vistas com multifuncionais (Apothéloz \& RechlerBéguelin, (1995) falam em poli-operadores). Todas elas têm, além disso, uma dimensão simultaneamente construtiva e intersubjetiva.

O discurso, à medida que alimenta a memória discursiva, fornece uma representação de seus estádios sucessivos, particularmente "formatando" as expressões referenciais, que, nesse sentido, operam como "chaves" (clues). Tal representação, no entanto, pode ser ela mesma manipulada e as expressões referenciais são precisamente um dos lugares onde a manipulação é não só possível, como visível.

Em outras palavras: a função das expressões referenciais não é apenas a de referir. Pelo contrário, como multifuncionais que são, elas contribuem para elaborar o sentido, indicando pontos de vista, assinalando direções argumentativas, sinalizando dificuldades de acesso ao referente, recategorizando os objetos presentes na memória discursiva.

O que foi aqui discutido permite verificar o importante papel desempenhado pelas expressões nominais na organização do texto e sua contribuição decisiva para a 
orientação argumentativa dos enunciados que o compõem e, em decorrência, para a construção interativa do sentido.

\section{REFERÊNCIAS}

APOTHÉLOZ, Denis; Marie-José REICHLER-BÉGUELIN (1995). "Construction de la référence et stratégies de désignation". In: BERRENDONNER, Alain; M-J. REICHLER-BEGUELIN (eds), p. 227-271.

APOTHÉLOZ, Denis (1995). "Nominalisations, réferents clandestins et anaphores atypiques". In: BERRENDONNER, A. e M-J REICHLER -BEGUELIN (eds), p.143-173.

APOTHÉLOZ, Denis; Catherine CHANET (1997). Défini et démonstratif dans les nominalisations. In: DE MULDER, Walter \& Carl VETTERS (eds.), Relations anaphoriques et (in)cohérence. Amsterdam: Rodopi, p.159-186.

AUTHIER, Jacqueline (1981). "Paroles tenues à distance". In: Materialités discursives. Presses Universitaires de Lille.

AUTHIER-REVUZ, Jacqueline. (1982). "Heterogeneité montrée et hétérogeneité constitutive: élémentes pour une approache de l'autre dans de discours. DRLAV 26, Paris, p. 91-151.

BERRENDONNER, Alain; Marie-José REICHLER-BEGUELIN (eds). (1995). Du syntagme nominal aux objets-de discours. SN complexes, nominalisations, anaphores. Tranel v. 23, Neuchâtel, Institute de Linguistique de l'Université de Neuchâtel.

CONTE, Elisabeth (1996a). "Anaphoric encapsulation”. Belgian Journal of Linguistics: Coherence and anaphora, v. 10, p.1-10.

(1996b). Dimostrativi nel testo: tra continuitá e discontinuitá referenziale. Lingua e Stile v. 31, p. 135-145.

CORBLIN, F. (1987). Indéfini, défini et démonstratif. Genève: Droz.

FRANCIS, Gill (1994). Labelling discourse: an aspect of nominal-group lexical cohesion In: COULTHARD, Malcolm (ed.), Advances in written text analysis. Londres: Routledge.

FRANCIS, Gill. \& M. LEONARD (1998). Le démonstratif dans les textes et dans la langue. Langue Française, v. 120, p. 5-20.

GARY-PRIEUR, M-N \& M. NOAILLY (1996). Demonstratifs insolites. Poétique, v. 105, p. 111-21.

KLEIBER, Georges (1983). Les démonstratifs (de)montrent-ils? Sur le sens reférentiel des adjectifs et pronoms démonstratifs. Le Français Moderne, v. 51/2, p. 99-117.

(1984). Sur la sémantique des descriptions demonstratives. Linguisticae Investigationes v. VIII/1, p.63-85.

- (1986). Adjectif démonstratif et article défini en anaphore fidèle. Actes du Colloque

"Déterminants: sintaxe et sémantique", Metz, dez.

KOCH, Ingedore G.Villaça (1984). Argumentação e linguagem. São Paulo: Cortez.

(1999). Expressões referenciais definidas e sua função textual. In: DUARTE, Lélia Parreira (org.),

Para sempre em mim: homenagem a Ângela Vaz Leão, Belo Horizonte: CESPUC, p. 138-150.

(1999). A referenciação textual como estratégia cognitivo-interacional. In: BARROS, Kazue S.

Monteiro, Produção Textual: interação, processamento, variação. Natal: Edufurn, p. 69-80. 
. (1999). Referenciação: Construção discursiva. Ensaio apresentado por ocasião do concurso para Titular em Análise do Discurso do IEL/UNICAMP.

KOCH, Ingedore G. V; Luiz Antônio MARCUSCHI (1998). Processos de referenciação na produção discursiva. D.E.L.T.A ., vol.14, no. especial, p.169-190.

MARCUSCHI, Luiz Antônio; Ingedore V. KOCH (no prelo). Estratégias de referenciação e progressão referencial na língua falada. In: ABAURRE, Maria Bernadete(org.), Gramática do Português Falado, vol. VIII, Campinas: Edunicamp.

MARSLEN - WILSON, William; E. LEVY; L. K. TYLER (1982). Producing interpretable discourse: the establishment and maintenance of reference. In: JARVELLA, R. J. \& W. KLEIN (eds.), Speech, Place, and Action. J. Wiley, p.339-378.

MONDADA, Lorenza; Danielle DUBOIS. Construction des objets de discours et catégorisation: une approche des processus de référentiation. In: A.BERRENDONNER \& M-J. REICHLER-BÉGUELIN (op. cit.), 273-302.

REICHLER-BÉGUÉLIN, M.J (1998). L’usage des SN démonstratifs dans les fables de La Fontaine. Langue Française 120: 95-109.

SCHWARZ, Monika. (2000). Indirekte Anaphern in Texten. Tübingen: Niemeyer.

VATER, Heinz (1984). Referenz und Detemination im Text. In: ROSEGREN, I., Sprache und Pragmatik., Lunder Symposium , p. 323-344. (1986). Einführung in die Referenzsemantik. Köln: Klage. 